OPEN ACCESS

Edited by: Horst Treib/maier

MODUL University Vienna, Austria

Reviewed by: Alexander Norta, Tallinn University of Technology, Estonia Henry Michael Kim, Schulich School of Business, York

University, Canada

*Correspondence: Ingrid Bauer bauer@ifi.uzh.ch

Specialty section:

This article was submitted to Non-Financial Blockchain,

a section of the journa

Frontiers in Blockchain

Received: 31 July 2019 Accepted: 30 December 2019 Published: 23 January 2020

Citation:

Bauer I, Zavolokina L, Leisibach F and Schwabe G (2020) Value Creation From a Decentralized Car Ledger.

Front. Blockchain 2:30 doi: 10.3389/fb/oc.2019.00030

\section{Value Creation From a Decentralized Car Ledger}

\author{
Ingrid Bauer*, Liudmila Zavolokina, Fabian Leisibach and Gerhard Schwabe \\ Information Management Research Group, Department for Informatics, University of Zurich, Zurich, Switzerland
}

Blockchain technology is expected to create a variety of new opportunities for businesses. Yet, little is known about how the technology actually enables to create value and how companies will be able to exploit true business value. However, without a clear understanding of the value creation potential from the technology, and corresponding adaption of business practices, the realization of value is doomed to failure. Hence, we contribute to this gap by exploring and explicating the specificities of value creation from blockchain in the ecosystem of a car. In the course of an exploratory case study analysis, over a time period of 2 years, we conducted three iterations of interviews and workshops with industry and blockchain experts from five diverse stakeholder groups. In brief, we provide early evidence that (1) blockchain enables value creation through: Distributed Product Innovation, Shared Operational Efficiency, and Controlled Customer Intimacy. Furthermore, we discuss our learnings for businesses in other domains aiming to leverage value from blockchain technology. We do so, by deriving guidelines for each blockchain value discipline. Furthermore, we give recommendations on how blockchain projects in ecosystems should approach multiple blockchain value potentials.

Keywords: blockchain, value creation, business models, value disciplines, blockchain business models

\section{INTRODUCTION}

Whenever a company embraces a new technology they aim for some form of value generation to either create or to sustain competitive advantage (Peppard and Ward, 2004). This also applies for blockchain, the technology that is expected to have great impact on a vast variety of industries (Morabito, 2017). Thus, since the introduction of bitcoin many companies started forming consortia, and spending time and resources exploring the potential of the technology with the hope of creating new business value for their companies. While on the one hand some skeptics warn of overhyped enthusiasm, the continuously growing worldwide spending on blockchain solutions show that there are quite a few others that still believe in the technology's business potential. According to the IDC's (International Data Corporation) statistics, between 2018 and 2019, the worldwide spending on blockchain solutions increased by $88.7 \%$ (from $\$ 1.5$ billion to $\$ 2.9$ billion). This amount is expected to continue growing with a compound annual growth rate of $76 \%$ and to reach $\$ 12.4$ billion in 2022 (Shirer et al., 2019). We have seen many proof-of-concepts showing that blockchain can provide valuable solutions to existing problems, for example mitigating transactional risk in the Bill of Lading process (Naerland et al., 2017), solving information asymmetries in the market for lemons (Notheisen et al., 2017) or increasing access to and incentivizes renewable energy sources through directly connecting consumers and prosumers via a decentralized market (Mengelkamp et al., 2018). However, despite great investments and promising benefits, it is not yet clear how companies will be able to exploit business value 
from the technology (Risius and Spohrer, 2017). Given this ambiguity, managers struggle in the adaption of blockchain to their businesses when moving from prototyping to implementation phase. However, the ability to understand how blockchain technology affects the business model and a corresponding adaption is key to achieve the aspired competitive advantage (Chesbrough, 2002; Teece, 2010). Taking a business perspective and focusing on the problems of managers, who aim to maximize the business value from the technology, we raise the following research question:

RQ: How can companies create value from a decentralized car ledger?

To answer this question, we conducted an exploratory study in the course of a larger Design Science Research Project (Hevner et al., 2004) called Car Dossier and applied the theoretical lens of Treacy and Wiersema (1993) to explicate the value potential from blockchain technology and derive generalizable characterizations of blockchain specific value potentials. Based on these insights we discuss our learning, of (1) how to manage each blockchain value discipline, and (2) how to approach multiple value disciplines.

Car Dossier is a joint European project including multiple stakeholders in the ecosystem of a car, ranging from a car importer and retailer, a road-traffic authority, an insurance company, and a car-sharing company, each acting as representatives for their respective industries. These diverse stakeholders collaborate to build a blockchain-based platform that allows to store all relevant data, during the life-cycle of a car, in order to better serve the car ecosystem in a variety of use-cases. Thus, these stakeholders will interact with each other on the basis of blockchain, in order to store and process data (Zavolokina et al., Forthcomming). In the following, we will use the term "the consortium," when we refer to collaborative activities including all of the above-mentioned stakeholders. When taking the specific lens of one of the stakeholders, we will use the following abbreviations: insurer, car retailer, road-traffic authority (RTA), Car Sharing Company (CSC).

To reach our research objective, we conducted semi-structured expert interviews, held workshops with all stakeholders individually and jointly, and used conceptual modeling of business processes and data-flows. Overall, we conducted three iterative exploration steps which resulted in: (1) a deeper understanding of the problem- and solution-space, (2) a thorough literature review and the adaption of scholarly concepts to explain observed phenomena and answer our RQ, and finally (3) derive guidelines from the results and discuss the learnings from our case to other application domains of blockchain. Additionally, a year later we conducted a fourth interview round in order to reevaluate the results, refine our concepts and to analyze how the blockchain value disciplines need to be approached during the development of the blockchain platform to enable early value creation for all stakeholders while at the same time allowing to reap individual benefits later.

The paper is structured as follows: in section Related Work we depart from digital technologies and digital innovation, we introduce blockchain, and describe the three value disciplines that served as our theoretical lens to analyze the business potential in the Car Dossier project. Section Methods describes the applied methods, and section Results presents the results. In section Discussion we derive guidelines from our case and discuss learnings for other practitioners. Finally, section Conclusion presents limitations, future outlook, and conclusions.

\section{RELATED WORK}

\section{Digital Technology and Innovation}

Many determinants need to be evaluated to define how a firm achieves and sustains competitive advantage. While the business model and the environment have been characterized as key determinants that directly influence a company's success, change is claimed to impact both, the business model and the environment in which businesses compete (Teece, 2007, 2010). Hence, change, that can arise from many sources (e.g., competitors, suppliers, customers, or technology) indirectly affects a company's performance (Teece, 2007). Today, digital technologies account for one of the greatest sources of change due to the continuously accelerating rate of innovation that again result in novel technologies (Chesbrough, 2002; Tidd and Bessant, 2011; Fichman et al., 2014). If companies miss out these opportunities, just as the formation of the internet economy has shown, digital technologies can very quickly change how business is being done and render existing business models obsolete (Hagler and Singer, 1999). This, makes of the key determinant of successful firms, namely the business model, not static but rather dynamic that requires constant innovation (Teece, 2010). Narrowing the concept of innovation, Fichman et al. (2014) defined digital innovation as "a product, process, or business model that is perceived as new, requires some significant changes on the part of adaptors, and is embodied in or enabled by IT." This definition incorporates both product (Yoo et al., 2010) and process innovation (Chesbrough, 2003; Desouza, 2011; Tidd and Bessant, 2011) but also business model innovation (Teece, 2010), a more recent class of innovation in IS research. Hence, following this definition, every new digital technology that requires significant change calls for digital innovation. Blockchain, a technology that comes with many new properties, is often claimed as being such a disruptive game changer with the potential to transform existing businesses or even create entirely new industries (Avital et al., 2016; Beck et al., 2017; Lindman et al., 2017). One prominent example, that has gained major attention from both academia and practice is its application of blockchain in the used-car market (Notheisen et al., 2017; Zavolokina et al., 2018). By enabling multiple stakeholders to at the same time collaborate and share the power, it promised to disrupt not only the used-car market but also other car-related industries (Zavolokina et al., Forthcomming). Thus, requires further in-depth analysis to understand how to harness its full potential (Morabito, 2017).

\section{Blockchain Technology}

In its essence, blockchain is a distributed ledger maintained and shared between nodes in a decentralized peer-to-peer network (Beck et al., 2016; Sharples and Domingue, 2016; 
Tschorsch and Scheuermann, 2016). All nodes share the same copy of the ledger, and changes are reflected immediately to all participants of the network. To ensure a single version of truth, all transactions are agreed upon through consensus. More specifically, entries in a blockchain are only accepted if they build on honest pervious entries and adhere to predefined protocols, ensuring tamper-proofness and validity (Naerland et al., 2017; Rückeshäuser, 2017). Despite various systematizations of the key characteristics of blockchain, delimiting it from mere distributed databases (Naerland et al., 2017), analyzing the interrelations of its key characteristics (Seebacher and Schüritz, 2017), or applying a layered perspective (Glaser, 2017), currently there is no unified definition of blockchain in literature and no common agreement whether or not all these different instantiations can be called blockchain (Wüst and Gervais, 2017). Yet, there are a few first approaches, that provide for example definitions for the bitcoin blockchain (Meiklejohn et al., 2016), blockchain applications (Lacity, 2018), or definitions of blockchain through different lenses: technical, business, and legal view of blockchain (Mougayar, 2016). A more generic and comprehensive definition is provided by Treiblmaier (2018, p. 547) who say, "A Blockchain is a digital, decentralized and distributed ledger in which transactions are logged and added in chronological order with the goal of creating permanent and tamper-proof records." The reason for the varying definitions of blockchain might be due to the fact that there is no "one and only" blockchain, but rather different instantiations of its key constructs. Specifically, variations in the properties regulating access rights to transactions have created grounds for classification. Dependent on the instantiation of the two dimensions (a) read and write access, and (b) validation rights to transactions, the authors classified blockchain in: public-permissionless, public-permissioned and privatepermissioned blockchains. While, in a public-permissionless blockchain unknown nodes are free to join the network, and read, write, and validate transactions, in a private-permissioned blockchain, only registered nodes have specific rights to perform transactions. Furthermore, a private-permissioned blockchain allows to differentiate between validating and non-validating peers, which regulates the validation of transactions and ledger maintenance. Compared to public-permissioned blockchain, this enables increased network security and increased scalability performance of the blockchain network (Li et al., 2017; $\mathrm{Xu}$ et al., 2017). Besides this classification, the concept of enterprise blockchain starts emerging in literature, which refer to blockchain systems that are adapted in a way to fit specific business needs (de Kruijff and Weigand, 2017; Morabito, 2017). There are many reasons for the necessity of business adaption of the technology. For example, businesses have to consider privacy concerns of their customers, their own business secrets, and not least legal restrictions to data protection (Hamm, 2016; Morabito, 2017; Lacity et al., 2018). This also applies for the Car Dossier project, the case that serves as unit of analysis for this research paper. Evaluating the trade-offs of transparency vs. anonymity with respect to read-, write-, and validation- access, considering latest data protection regulations, as well as the tradeoffs with respect to performance of transaction processing, the consortium decided to use a private-permissioned blockchain.
Comparing the chosen blockchain to centralized technologies, these were legally and organizationally not acceptable for the stakeholders (Zavolokina et al., Forthcomming). Finally, other distributed technologies might be available, but at that point of time those were not sufficiently mature to be accepted for this project. Besides the Car Dossier project, there are several other projects that have started to work on the idea of a digital blockchain-based dossier. Examples are cartifcar, Car eWallet, or Mobi. From a more academic perspective the solution approach of using blockchain to address issues in the market for lemons has been first described by Notheisen et al. (2017). Yet, a thorough investigation of the business potential of blockchain technology and especially its application in the car ecosystem is missing. Thus, we follow the calls for further research in this area (Avital et al., 2016; Rückeshäuser, 2017; Seebacher and Schüritz, 2017).

\section{Value Disciplines}

To explicate potential business value of blockchain we utilized the value disciplines initially described by Treacy and Wiersema (1993). They suggest that businesses must select and excel in one of the three value disciplines: Product Leadership, Customer Intimacy, or Operational Excellence, while remaining competitive at the other two. According to the authors, product leadership "means offering customers leading-edge products and services that consistently enhance the customer's use or application of the product, thereby making rivals' goods obsolete" (Treacy and Wiersema, 1993). Excellence in customer intimacy refers to a company's superior ability to match exactly the individual customer needs by segmenting and targeting specifically, compared to its competitors. Finally, according to Treacy and Wiersema (1993), companies excelling in operational efficiency serve the customers' needs through providing products and services with minimal inconvenience and at the lowest costs possible. Thus, the goal of each company should be to align and focus the operating model on one of these three value disciplines (Hagler and Singer, 1999; Osterwalder and Pigneur, 2010). As the computer business exemplified, the sudden drastic reduction in interaction costs changed the way companies exchanged goods and services and opened access to unexploited value that was quickly grasped by specialists rather than generalists (Hagler and Singer, 1999). Blockchain provides similar potential to reduce transaction costs even further (Beck et al., 2016; Davidson et al., 2016; Iansiti and Lakhani, 2017), and especially on the application layer provides greater possibility to specialize and focus on business operations (Glaser, 2017). Furthermore, researchers argue that in order to prepare for the blockchain future, companies will need to identify their distinct use-cases, which require varying approaches (Lacity et al., 2018). Hence, exploring value creation through the value disciplines (Treacy and Wiersema, 1993) provides a good tool to analyze the business potential in the Car Dossier project. Furthermore, given the novelty of the technology and the widereaching concept of digital innovation, spanning product, process and business model, through the value disciplines lens we can address all three. This is because on the one hand the value disciplines are broad in the sense that they incorporate the 
view on a company's culture, business processes, management and IT systems (Treacy and Wiersema, 1993), and support key IT design decisions (Eichen, 2006). On the other hand, they give the necessary focus to exploit specific customer values and help to explicate these for our stakeholders on a more operational level. To be comprehensive, Treacy and Wiersema (1993) also discuss "Masters of Two," companies that successfully manage and excel in two value disciplines. In order to achieve this, companies need to resolve the inherent tension of each value disciplines' distinct operating model. Yet, they argue that while currently mastering at least one value discipline is a minimum to be successful on the market, "chances are that the big winners of the future will have mastered two" (Treacy and Wiersema, 1993, p. 86). In the internet economy this resulted again in novel business models (Osterwalder and Pigneur, 2010). However, how this evolves with the blockchain revolution is yet unknown.

\section{METHODS}

The lack of knowledge of how business value can be created from blockchain is a common problem of current blockchain projects. Thus, informed by a problem with practical relevance (Hevner et al., 2004) we explored this general problem in the course of a larger Design Science Research project, the Car Dossier. However, in this paper we solely focus on explicating the value potential from the technology through qualitative data analysis. Drawing on the findings from our case, it is our goal to derive guidelines for the design of a blockchain systems that will allow business value creation for practitioners through a better understanding of the specific value potentials of blockchain (Hevner et al., 2004; Gregor, 2006; Gregor et al., 2013).

Despite the focus on one project, the multitude and diversity of project partners in this project greatly represent the car ecosystem and hence serve as an excellent subject for examination. Overall, this exploratory analysis is grounded on the following data sources: (1) in total 16 stakeholder interviews (between 50 and $70 \mathrm{~min}$. each) conducted in four rounds over a time period of 2 years, (2) four consortium workshops (between 40 and $60 \mathrm{~min}$. each), (3) conceptual models, in the form of business process flows or data-models and, (4) further company information that were provided by the stakeholders individually and jointly. The interviews and workshops served the purpose of eliciting information and evaluating results. All interviewees were either subject matter experts or C-Level managers from the partner companies and active participants in the Car Dossier project, who participate in regular design and development sessions. Hence, all interview participants shared a common understanding of the blockchain technology they were questioned about. Throughout these iterative exploration and evaluation loops conceptual models were developed and refined. All interviews were conducted as semi-structured interviews (Myers and Newman, 2007) and later transcribed and analyzed with qualitative data analysis software. For the coding, an open coding process was used (Saldaña, 2009) and the coded units were phrases, sentences and paragraphs (Weber, 1990). To increase internal validity and ensure a shared conception of reflection, the codebook was crosschecked between the authors (Weston et al., 2001). The goals, applied methods, and conceptual models that we used during the four iterative data collection steps followed both, the guidelines for theory-generating design science research (Beck et al., 2013), and the guidelines for applying the Value Disciplines as a tool to understand and shape IT decisions (Eichen, 2006), and can be summarized as follows:

(1) First we aimed for a clear understanding of the problem and solution space (Eichen, 2006; Beck et al., 2013) and therefore performed two semi-structured interview (Myers and Newman, 2007) rounds. (1a) the first interviews were conducted between May and July 2017. Each partner company was interviewed individually to create a general understanding of the specific problem domain (Eichen, 2006) of each partner. The questions addressed the overall business model of each company, the specific business areas that are related to the Car Dossier project, and finally the goals of each stakeholder with respect to the joint project. This resulted in several process diagrams, documenting current business processes. The resulting business processes diagrams, as well as the data and system architecture models were then evaluated with the project partners individually. (1b) a second interview round was conducted between September and October 2017 and served to further narrow the problem area (Eichen, 2006) of each stakeholder, as well as the consortium. Thus, we asked each partner company to describe their problem in their own words and outline potential ways for data and information sharing through the joint blockchain infrastructure. This enabled to model future data and process flows (Chen, 1976) for the ecosystem via the planned blockchain architecture which were then evaluated in a joint consortium workshop. To exemplify this, we have added in the supplementary material one process diagram that shows results of interview-round 1a, the current process flows, in this case of a car import process (Supplementary Figure 1a), as well as process diagram that resulted from the second interview rounds (Supplementary Figure 1b) that show the envisioned process flows via the car dossier.

(2) Next, on the basis of these thorough insights, coupled with knowledge from scholarly theories introduced earlier, we derived ideas for future value creation mechanisms. This resulted in 15 high-level business concepts (Beck et al., 2013) each centering around one of the previously introduced value disciplines (Eichen, 2006) targeting the car ecosystem. The idea behind this was to provide each stakeholder and the consortium with three options, focusing on a choice between the value disciplines.

(3) These business concepts were evaluated again through interviews with stakeholders individually and the consortium (Beck et al., 2013) which took place in March and April 2018. During this third interview round, always two stakeholders from each company participated in the 
interviews. Here we specifically focused on the interrelation of the business concepts with the technology (Eichen, 2006). Finally, when analyzing these interviews we used the value discipline lenses to guide the coding process, these formed our high-level categories. However, within these categories we used a bottom-up open coding process, meaning we moved from codes that emerged to categories and then to theory (Saldaña, 2009). This was done to refine each value discipline and allowed us to explicate the value potential that is specific about blockchain and abstract knowledge for value creating blockchain design decisions (Eichen, 2006; Beck et al., 2013).

(4) Almost a year later, between February and April 2019, we again conducted interviews with the Car Dossier project. One specific focus of the interviews were again the business model and the value potential for each partner company as well as the consortium. The goal was to reevaluate our results, gain a deeper understanding of the blockchain value potentials through targeted questions, and to capture any changes that might have occurred over time. These interviews were conducted by an independent person, who has a good understanding of the value potential concept, however is not biased as being an author. These interviews were coded through the previously identified blockchain value discipline lenses, but again with an opencoding toward refinement as well as a time-perspective (Saldaña, 2009).

Table 1 gives an overview of all workshops and interviews that were conducted for data collection and evaluation. Furthermore, the roles and affiliation of the interviewees are stated to clarify belonging of the quotes presented in the Results section. Next to the stakeholders mentioned earlier, the project also involves a Software Company which also participated in the interviews. The Software Company is responsible for system

TABLE 1 | Summary of data collection and evaluation.

\begin{tabular}{|c|c|c|c|c|c|}
\hline $\begin{array}{l}\text { Interview round } \\
\text { and timing }\end{array}$ & $\begin{array}{l}\text { Purpose and goal of the } \\
\text { interviews }\end{array}$ & Affiliation & \multicolumn{2}{|c|}{$\begin{array}{l}\text { Role and short name used in to present } \\
\text { the quotes in the results section) }\end{array}$} & Results \\
\hline \multirow[t]{5}{*}{$\begin{array}{l}\text { 1st Interview round } \\
\text { May-July } 2017\end{array}$} & \multirow[t]{5}{*}{$\begin{array}{l}\text { Understand the problem and } \\
\text { solution space }\end{array}$} & Software company & \multicolumn{2}{|c|}{ Car Dossier project management } & $\begin{array}{l}\text { Process diagrams documenting current } \\
\text { business processes flows }\end{array}$ \\
\hline & & Importer and retailer & \multicolumn{2}{|l|}{ C-Level management } & \\
\hline & & & \multicolumn{2}{|l|}{ Project manager } & \\
\hline & & Insurance company & \multicolumn{2}{|l|}{ C-Level management } & \\
\hline & & Road Traffic Authority & \multicolumn{2}{|l|}{ B-Level management } & \\
\hline \multirow{5}{*}{$\begin{array}{l}\text { 2nd Interview round } \\
\text { October/November } \\
2017\end{array}$} & \multirow{5}{*}{ Narrowing the problem-space } & Software company & \multicolumn{2}{|c|}{ Car Dossier project management } & \multirow{5}{*}{$\begin{array}{l}\text { Data model and Process-flows for the } \\
\text { planned blockchain architecture of the } \\
\text { ecosystem } 15 \text { high-level business } \\
\text { concepts each centering around one of } \\
\text { the value disciplines }\end{array}$} \\
\hline & & Research institute & \multicolumn{2}{|l|}{ Project management } & \\
\hline & & Insurance company & \multicolumn{2}{|l|}{ C-Level management } & \\
\hline & & Road traffic authority & \multicolumn{2}{|l|}{ C-Level management } & \\
\hline & & Consortium workshop & \multicolumn{2}{|c|}{ Representatives from all stakeholder groups } & \\
\hline \multirow{11}{*}{$\begin{array}{l}\text { 3rd interview round } \\
\text { March/April } 2018\end{array}$} & \multirow{11}{*}{$\begin{array}{l}\text { Evaluation of the results from } \\
\text { the prior phase (Business model } \\
\text { concepts) in-depth analysis of } \\
\text { the interrelation of the business } \\
\text { concepts with blockchain } \\
\text { technology }\end{array}$} & Software company & $\begin{array}{l}\text { Car Dossier project } \\
\text { management }\end{array}$ & 3_SC_PM_1 & \multirow{11}{*}{$\begin{array}{l}\text { Model that depicts how blockchain enables } \\
\text { value creation } \\
\text { Blockchain value potentials and guidelines } \\
\text { for businesses }\end{array}$} \\
\hline & & & $\begin{array}{l}\text { Car Dossier project } \\
\text { management }\end{array}$ & 3_SC_PM_2 & \\
\hline & & Importer and retailer & Project manager & 3_IR_M & \\
\hline & & & Subject matter expert & 3_IR_E & \\
\hline & & Insurance company & C-Level management & 3_IC_M & \\
\hline & & & Subject matter expert & 3_IC_E & \\
\hline & & Road traffic authority & C-Level management & 3_RTA_M & \\
\hline & & & Subject matter expert & 3_RTA_E & \\
\hline & & Car sharing company & C-Level management & 3_CSC_M & \\
\hline & & & Subject matter expert & 3_CSC_E & \\
\hline & & Consortium workshop & \multicolumn{2}{|c|}{ Representatives from all stakeholder groups } & \\
\hline \multirow[t]{4}{*}{$\begin{array}{l}\text { 4th interview round } \\
\text { Feb-April } 2019\end{array}$} & \multirow{4}{*}{$\begin{array}{l}\text { Reevaluation of prior results, } \\
\text { refinement of concepts and } \\
\text { addition of the time-perspective }\end{array}$} & Software company & $\begin{array}{l}\text { Car Dossier project } \\
\text { management }\end{array}$ & 4_SC_PM_1 & \multirow[t]{4}{*}{$\begin{array}{l}\text { Refined value potentials Time-reflected } \\
\text { view on blockchain value creation }\end{array}$} \\
\hline & & Research institute & Project management & 4_RI_M & \\
\hline & & Insurance company & C-Level management & 4_IC_M & \\
\hline & & Road traffic authority & C-Level management & 4_RTA_M & \\
\hline
\end{tabular}


development and project management activities. Thus, they share the same understanding of the technology that they were questioned about, as the other interviewees. Besides that, during the reevaluation phase also the project manager from the research institute was interviewed who was engaged since the very beginning with the project and has had mainly the consortium's perspective.

\section{RESULTS}

In this section we present our results from the qualitative analysis of the third step, the evaluation of the value discipline centered business concepts. We do so by giving specific examples from the Car Dossier project for each of the value disciplines and underpin these with code units. Besides that, we show the validity of our results by providing additional quotes from our fourth interview round. For each value discipline, we will focus on one business concept and explain on the horizontal level the pervasive character of blockchain enabled value creation. Figure 1 illustrates the blockchain characteristics that emerged as code units from the interview analysis and which were categorized into blockchain capabilities. Finally, enabled by the blockchain characteristics, the blockchain capabilities enable the manifestations of the blockchain value disciplines: Distributed Product Innovation, Shared Operational Efficiency, and Controlled Customer Intimacy. The resulting blockchain characteristics and capabilities will be explained in detail in section Distributed Product Innovation. In section Shared Operational Efficiency and Controlled Customer Intimacy will only shortly exemplify these but rather keep the focus on our main contribution, the specificities of value creation through blockchain. At the end of each subsection a table will summarize the result.

\section{Distributed Product Innovation}

From the first two interview rounds we learned that one key problem the consortium aims to solve through blockchain is the information asymmetry between buyers and sellers during the sale of a used car (market for lemons problem in academic literature; Akerlof, 1970). This also marks the initial case that brought together the consortium, namely addressing this information asymmetry through a blockchain-based digital dossier, a car dossier, that stores all relevant events during the lifecycle of a car. Thus, the stakeholders aim to store and process all car-related data and information, and jointly create a car dossier for all cars on the market, aiming to reduce asymmetries and increase market transparency (Bauer et al., 2019). Similar solutions like an Eurotax or a Carfax report might exist today, yet given their shortcomings (e.g., the lack of trust toward one single provider and the lack of trust in data quality; or inconsistency and incompleteness of a central registry of one provider; and high costs that do not justify the benefits) they only showed limited impact on the market so far. Thus, the consortium decided to address the issues prevailing the used car market today with a novel approach. This novel approach foresees a joint infrastructure, where the participating firms will be able to process data in a secure manner. The justification for blockchain to solve this problem in general was evaluated thoroughly by the stakeholders and also in academia (Notheisen et al., 2017). Still a variety of alternatives exist in how specifically IT might approach this problem. Thus, by questioning through the value discipline lens, we were able to understand the strategic focus

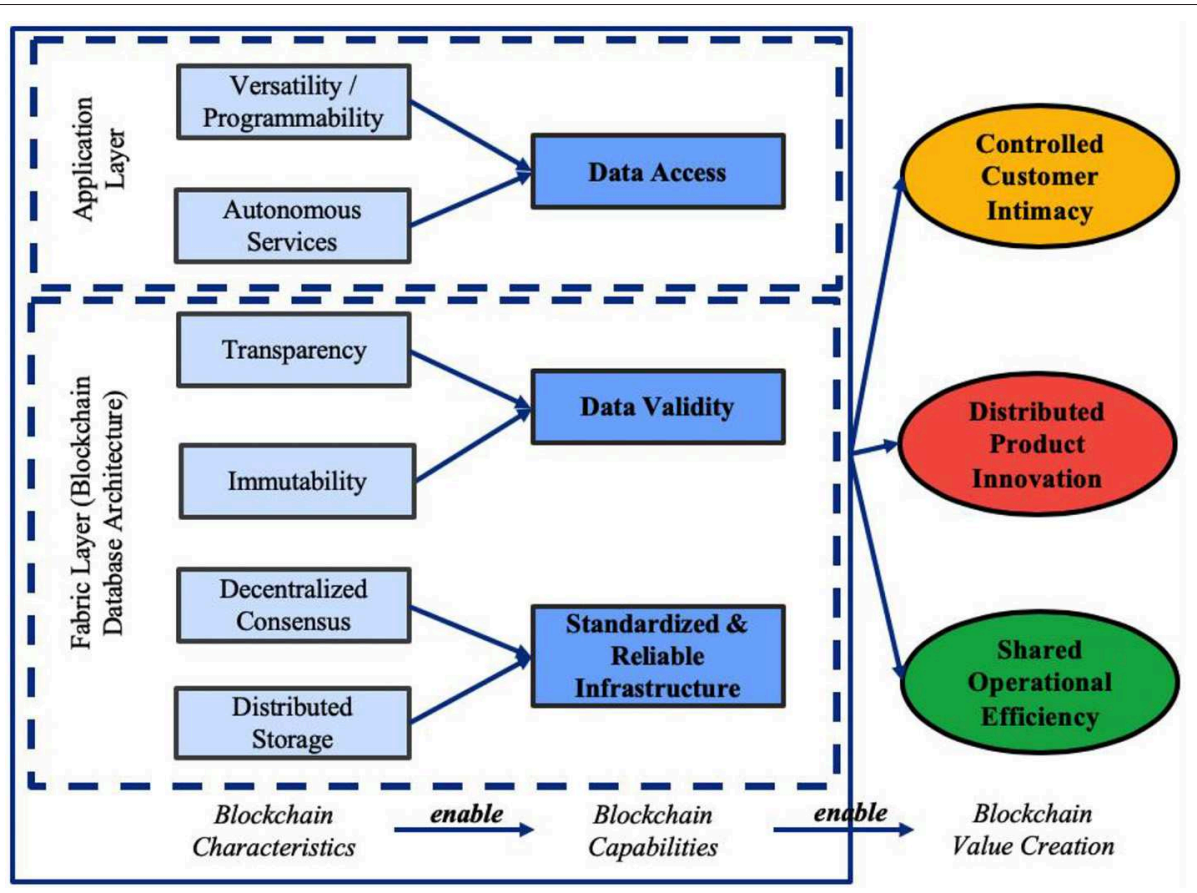

FIGURE 1 | Blockchain enabled value creation. 
of the consortium and the pervasive blockchain characteristics they rely on to create customer value through a joint blockchainbased infrastructure.

The consortium showed agreement that they aim for product leadership through providing an innovative solution to a yet unserved market. Besides little disagreement whether to classify it as a product or service, the interviewees mentioned: "With the consortium glasses car dossier clearly is a service innovation which solves a clear need, that customer have, but which they might not necessarily be aware of today, (...) I would say there is great unserved potential to leverage through providing this transparency with car dossier." (3_IC_E). Another said, "It is for sure a quite complex product, however also a very innovative one for our customers" (3_CSC_M). Once the value for the users was clearly delineated, during the discussions with the consortium, we further asked about the novelty of the solution and the necessity of blockchain for creating such a digital car dossier. In its essence, the two rationales that emphasized the need for blockchain are the need for collaboration and the sharing of power. The responses were pretty clear, "Blockchain is the only technology, as of today, that allows all of us to work together." (3_RTA_M). To overcome the shortcomings of currently existing solutions, in particular the lack of comprehensive and trusted data, the stakeholders realized that they needed to join forces and work together with other firms in their industry but also with firms from other (car-related) industries. While the project today only involves one representative from the major car related industries, the vision of the consortium is to build an architecture that will allow also direct competitors to join at a later stage. Or as mentioned by the project manager, “(...) all our partners support this, the platform only makes sense if all competitors will also be on it (...)" (4_SC_PM_1), only then they would be able to create a complete and consistent car history for all cars in their target market. Another framed this in a paradoxon, "Of course we could solve these collaboration challenges we previously had differently but if we would do so, and evaluate the resulting technology neutrally, we would end up with exactly a solution as blockchain" (3_SC_PM_1). When we dug deeper and asked what specifically about blockchain it was that enabled them to collaborate and jointly build a novel architecture that will eventually allow to provide a car dossier, we managed to ascertain the key blockchain characteristics they rely on. Namely on the one hand, decentralized consensus and distributed storage of data. As these two blockchain characteristics were always used jointly or interchangeably to explain the key blockchain capabilities that they relied on, during the coding process we categorized these as the blockchain capabilities enabling: standardized and reliable infrastructure. For example, one manager explained: "So many changes occur during the life-cycle of a car, sometimes even on a daily basis. Thus, it would not be enough to get a snapshot every now and then, (...) but being able to dynamically have insights to all changes and being sure about these entries is what blockchainconsensus enables us (...)." (3_IR_M). More specifically it enables collaboration but at the same time sharing of power. Sharing of power enabled through decentralization, turned out as being essential given the lack of trust that exists between firms but also the trust toward the solution otherwise. If the solution was not a decentralized data-base system, who should then be in charge of such a central data collator? This would rather create a threat than an opportunity to businesses in the car ecosystem. On the other hand, the blockchain characteristics, transparency and immutability of transactions were mentioned by the consortium as key characteristics that allow increased data validity. E.g., "The security aspect of blockchain is something of very high priority for us. Data must be safe, immutable and not manipulable by anybody. (...) Being sure about the validity of the data is the alpha and omega for our business, which blockchain provides us now." (3_RTA_M). Another mentioned, "one key differentiator it brings for us, is that we can clearly say that we respect data security and that we are even pioneers here (...) that is a quality label of car dossier" (4_IC_M). Again, these two characteristics were mentioned not only once, however when the partners, for example referred to transparency, they always also emphasized again the reliability of the data entry that they aim to achieve. E.g." "Through mutual verification we can now trust the data entry of others, and even use what they added to the database to further process it." (3_RTA_E).

Finally, a third blockchain capability emerged from the characteristics, programmability/versatility and autonomous services, namely the ability to create a decentralized data access. However, when talking about these blockchain characteristics the interviewees mainly referred to the adaptable application logic and the possibilities for implementing smart services, that build on the underlying key data structure and infrastructure logic. One C-Level Manager described this nicely, "So the business idea is to provide a platform (...) that allows to extract data and work up individual business cases. Since we have created an ecosystem where each partner might have different interests. In fact, the car dossier infrastructure is the base or the core from which one can extract some elements to work of certain use cases." (4_RTA_M). Thus, also in accordance with the literature introduced earlier (Glaser, 2017), we grouped the first two capabilities to the fabric layer and the third capability to the application layer. For the car dossier, a platform that is created jointly from multiple independent stakeholders, especially the adaptability to their own infrastructure was mentioned as the most important factor. For instance, one manager explained: "We are building a really innovative product with many original owners, thus, allowing individual integration but also aligning different things from different owners is really essential here." (3_SC_PM_1).

In sum, from our case we learned that blockchain enables product innovation, through enabling companies to create data access and data validity and a reliable and standardized infrastructure which in turn draws on key blockchain characteristics (shown in Figure 1). However, as the above delineated results show, the car dossier is not an innovation of one company alone but arises from the distributed efforts of multiple stakeholders. Or as one manager framed it, in this project "all help each other to get better, and this is only possible together." (3_SC_PM_1). The stakeholders are all experienced in the car market, and also pursue the same interests, which is to serve the needs of buyers and sellers of used cars through providing a novel information infrastructure which eventually allows to extract a novel information product, a car dossier. Yet especially, "the network of partners in this consortium is essential to achieve early market entry and leadership." (3_SC_PM_2). All 
stakeholders mentioned that they were aware of this customer need before, yet they lacked the necessary capabilities that enables them provide a trusted comprehensive solution. Thus, the key difference blockchain makes, is that it goes beyond simply product innovation but enables companies to collaborate and innovate in a distributed manner. Hence, through the creation of a new product, the car dossier that has multiple owners, allows the stakeholders to create value and excel through distributed product innovation. A summary description and a key code are presented below in Table 2 .

\section{Shared Operational Efficiency}

Removing mistrust between industry players, blockchain further promises each company to improve operations through sharing processes and leveraging cross-organizational efficiencies. "All around the ecosystem of the car partners can enhance and automate their processes, thus achieve efficiency gains" (4_SC_PM_1). Hence, those companies that focus on the possibilities of reducing transaction costs through sharing processes via blockchain, can achieve shared operational excellence. In the Car Dossier project this is yet another important business case for most stakeholders. "The collaboration with regards to business processes is where I see the great value lever." (3_IR_M). Another stakeholder mentioned: "Blockchain finally allows us to achieve agreement with regards to business processes and resolve inefficiencies." (3_RTA_E).

To give a specific example, todays information flows between customers, car importer, customs and the RTA are characterized by manual processes relying on physical documentation. This physical document handling is not only prone to error for the individual companies like authorities and the importer, but also inconvenient and leads to doubled work for both, the customers and the stakeholders. "I think one problem that is being solved is the friction we have in the currently partially poor data quality (...) another aspect is the trust of customer in our business" (4_RTA_M). Today, customers have to provide similar details, to multiple stakeholders, in physical forms, and time-consuming ways. One example for this is the import form, a central document during the import process of a car that changes hands multiple times, not only between a customer and stakeholders, but also between businesses directly. "The importer records the document, customs do, the insurers take similar notes, you see there are a lot of points for failure" (4_RTA_M). Thus, providing great potential for reducing transactions costs through a single point of truth. Adding to that, blockchain particularly

TABLE 2 | Summary joint product innovation.

\begin{tabular}{ll}
\hline $\begin{array}{l}\text { Blockchain value } \\
\text { creation }\end{array}$ & $\begin{array}{l}\text { Description of identified concept supported by a key } \\
\text { code }\end{array}$ \\
\hline $\begin{array}{l}\text { Distributed product } \\
\text { innovation }\end{array}$ & $\begin{array}{l}\text { Blockchain enables to collaborate and innovate new } \\
\text { products and services across organizations in a distributed } \\
\text { manner. } \\
\text { "“Through mutual verification we can now trust the data } \\
\text { entry of others, and even use what they added to the } \\
\text { database to further process it." (3_RTA_E)." }\end{array}$
\end{tabular}

enables cost reduction across organizations. One interviewee stated: "Yes I am pretty sure that, as of today, blockchain is the only technology that allows us to resolve these inefficiencies and jointly digitize these things." (3_RTA_E). When we further asked "why blockchain," they again most importantly referred to the security aspects of blockchain. "Being sure about data validity and knowing where it comes from, and having the possibility to trace things, is key for authorities like us" (3_RTA_M). Also, the importer agreed to the necessity of blockchain to digitize these important, and often shared documents in a tamper-proof manner. When we asked conversely, they also mentioned the lack of trust in data validity and the lack of possibilities to share these documents in a secure and reliable way as the key reason for not being able to resolve these inefficiencies so far. Additionally, one manager emphasized "almost all business cases which target crossfirm operational processes, depend on the penetration, meaning how many cars we have in the car dossier." (4_IC_M), which on the one hand relates back to the overall vision of the project, namely to include as many firms from the car related industries as possible, on the other hand highlights the necessity of an infrastructural basis like blockchain, that allows for collaboration but also competition, as explained earlier.

With respect to the beneficiaries, the stakeholders agreed that this would lead to increased customer convenience and minimize points of failure at both ends, authorities like RTA and end users (e.g., owners of a car), but also businesses, for example operating as car importer. Next to user convenience (both private and business users), they further stressed the potential for cost reduction that can be leveraged from both standardization and integration of todays fragmented systems: "The data in general we could also get from customers, that is not the biggest issue today, where I see the biggest value is in the integration of the systems, that leads to cost reductions. This integration aspect, combined with reliable digital data exchange will also allow us to further optimize other processes, for example our fleet management." (3_IR_M). Finally, on the application layer this also allows to automate cross-organizational business processes, "these two aspects go hand-in-hand, namely that all firms have the same view on the data which cannot diverge, and that they can automate the overarching processes nicely" (4_SC_M_1).

Along these lines we exemplified that blockchain also has the potential to enable sharing of critical processes and documents across organizations, and leverage value through cross-organizational sharing. Nonetheless, the technology still allows each stakeholder to set their individual foci, e.g., on customer convenience like the RTA, or on reducing operational costs like the importer. In other words, "so we have the joint platform (...) and on top of that each company can realize its own efficiency cases" (4_IC_M). Hence, all in all blockchain enables both players to excel through shared operational efficiency (Table 3).

\section{Controlled Customer Intimacy}

Through collaboration over a shared and transparent ledger, the stakeholders discovered that the technology also creates opportunities to even further customize their existing products and services according to niche customer preferences. Or to put 
TABLE 3 | Summary shared operational efficiency.

\begin{tabular}{ll}
$\begin{array}{l}\text { Blockchain value } \\
\text { creation }\end{array}$ & $\begin{array}{l}\text { Description of identified concept supported by a key } \\
\text { code }\end{array}$ \\
\hline $\begin{array}{l}\text { Shared operational } \\
\text { efficiency }\end{array}$ & $\begin{array}{l}\text { Blockchain enables companies to minimize overhead costs } \\
\text { through sharing processes. } \\
\text { "These two aspects go hand-in-hand, namely that all firms } \\
\text { have the same view on the data which cannot diverge, and } \\
\text { that the one can automate the overarching processes nicely." }\end{array}$
\end{tabular}

it in their words, "for sure, they (the project partners) are also interested in having this data to make more personalized offerings for their clients." (4_RI_M). Hence, allowing the stakeholders to create additional value. This is yet again possible only through increased access to valid data and, just as importantly, through a reliable and standardized infrastructure. However, access to customer data over the blockchain requires the consent of that customer, "It (the data) is not public. So, to think about the technical implementation, we're using Corda, which is not a public blockchain itself, in the way it gives us benefit for privacy because we have the personal data of car owners. In general, the concept is that you can share your data and you have control over your data. So you know who you share the data with and you can revoke the access that you have given to somebody at any time." (4_RI_M). Thus, blockchain enables value creation through customization, however in a controlled manner.

One example from our Car Dossier project is the possibility to customize insurance services. Or as one partner summarized it: "Today our insurance premiums and services are packaged the way they are because we lack knowledge. For example, about the quality of a car. Thus, simply said, we have to put all customers in the same pot. Now, through blockchain and the Car Dossier project we would be able to tailor our services better to our customers' needs because we can be sure that we are talking about that specific car with that specificities." (3_IC_E). Or as another put it more succinctly "blockchain enables us to customize our products better, one example could be object pricing" (3_IC_M). With respect to the blockchain capabilities they also further elaborated and explained, for instance, increased data access and data validity as follows: "We could also give discounts dynamically because through the blockchain system we can query information, for example about mileage, regularly and hence give you a plus or minus on a quarterly-basis (...). The data might have been collected through one of our partners, or even through dongles automatically, and we need not to bother the customer for that, since we can be sure about the correctness of the data. (...) Plus, we can get access to more data, for example from the importer or the manufacturer, and make more precise evaluations." (3_IC_M). When we asked why they did not leverage this potential before, we could again elicit that it is specifically the interplay of all three blockchain capabilities that enables them now to create value through increased customer intimacy. One expert framed it simply: "It is a matter of trust. Ok, maybe we could trust the importer we collaborate in this project with, however, thinking further we also want to integrate other car importer and retailer which we maybe cannot trust." (3_IC_E). Yet, blockchain adds a specificity to the customization of products and services: "We
TABLE 4 | Summary controlled customer intimacy.

\begin{tabular}{ll}
$\begin{array}{l}\text { Blockchain value } \\
\text { creation }\end{array}$ & $\begin{array}{l}\text { Description of identified concept supported by a key } \\
\text { code }\end{array}$ \\
\hline $\begin{array}{l}\text { Controlled customer } \\
\text { intimacy }\end{array}$ & $\begin{array}{l}\text { Blockchain enables companies to achieve excellence in } \\
\text { customer intimacy, however, in a customer-controlled } \\
\text { manner. } \\
\text { "We have to be careful here. I think intimacy is an unstable } \\
\text { balance with blockchain. It is much more a give and take } \\
\text { then before. (...) You'll have to build up the trust from the } \\
\text { customers to the insurance companies first, so that they } \\
\text { will allow you access into their data." }\end{array}$
\end{tabular}

have to be careful here. I think intimacy is an unstable balance with blockchain. It is much more a give and take then before. (...) You'll have to build up the trust from the customers to the insurance companies first, so that they will allow you access into their data." (3_SC_PM_1). What the manager refers to in this specific case also emerged in other examples and hence, we classified it as control by the customer. Since all development efforts of the project build on the principle, "we make the customer, the owner of the data, responsible for his or her data him-/herself." (3_SC_PM_2), customers will no longer have to acquiesce everything. In turn, for our partners this means, "only the ones that play fairly get a chance to better customer intimacy. That is something new for businesses we all have to get used to." (3_SC_PM_1). Finally, as the project matured, it also emerged that advantages through increased customization require the partners also to consider multi-party access rights to data. Some data in the system might be provided by one user but belong to another user, for example an insurance company might store the insurance certificate for their customers in the blockchain, however also the owner (from whom the insurance certificate was provided) has rights over this data event. Thus, as mentioned by the manager from the insurance company, "We have to get into the ecosystem thinking and learn how it works. So that if we need data we need authorized access sometimes not only by one-to-one connections." (4_IC_M).

All in all, this clearly exemplifies that blockchain allows companies to create value through controlled customer intimacy. On the one hand, the increased access to valid data allows companies to better understand their customers and tailor their services accordingly. On the other hand, standardization of infrastructure and data formats create low friction for access and inhibit high costs. Yet, the relationships to customers experiences a twist, in a way that they gain increased control over their customization. Furthermore, to achieve even better customization they will need to consider not only 1:1 relationship but ask for access from multiple parties. Thus, value creation through controlled customization, over blockchain will only function for stakeholders "that rule this game through fair give and take" (3_SC_PM_1) (Table 4).

\section{DISCUSSION}

From our conceptualization and evaluation steps with the Car Dossier project, we collected first evidence for how blockchain can enable companies to create value in the car ecosystem. 
TABLE 5 | Guidelines for blockchain value creation.

\begin{tabular}{ll}
\hline $\begin{array}{l}\text { Blockchain value } \\
\text { creation }\end{array}$ & Guidelines for other businesses \\
\hline $\begin{array}{l}\text { Distributed product } \\
\text { innovation }\end{array}$ & $\begin{array}{l}\text { Put on your consortium glasses and focus on unserved } \\
\text { potential in the ecosystem rather than your industry } \\
\text { segment. }\end{array}$ \\
$\begin{array}{l}\text { Shared operational } \\
\text { efficiency }\end{array}$ & $\begin{array}{l}\text { Resolve cross-organizational inefficiencies but set your } \\
\text { own focus to leverage the full potential for your business. }\end{array}$ \\
$\begin{array}{l}\text { Controlled customer } \\
\text { intimacy }\end{array}$ & $\begin{array}{l}\text { Be aware of the changing (power) relationships and } \\
\text { focus on understanding the data-structure and building } \\
\text { trusted-relationship to your customers and data } \\
\text { co-creators. }\end{array}$ \\
\hline
\end{tabular}

Drawing on the blockchain characteristics, which enable the capabilities, our findings suggest blockchain value creation through: Distributed Product Innovation, Shared Operational Efficiencies, and Controlled Customer Intimacy. These insights are valuable for both researchers and practitioners as they help to understand the potential business value that lies within blockchain platforms. Further, on the basis of these results we derive guidelines that help to guide design decisions in a way to enable business value realization from the technology. In the sections below, we will first discuss what our learnings can mean for other businesses aiming to create value from blockchain. Table 5 summarizes the guidelines for each of the blockchain value disciplines. Subsequently, based on our observations over a time span of two-and-a half years, we further discuss how other consortium blockchain projects should approach the development of the blockchain platform to enable early value creation for all stakeholders while at the same time allowing to reap individual benefits later. These insights will help other projects, aiming to create value from blockchain technology, to move from use case prototpying to implemention phase.

All in all, we provide first evidence for the academic question raised above and the problems managers currently face. Further, previous research has claimed that blockchain has the potential for disrupting businesses (Beck et al., 2017; Lindman et al., 2017), we add to this by demonstrating how this can be realized in the car ecosystem. More precisely we reveal the blockchain traits on a vertical level, that penetrate business practices. During our qualitative analysis it emerged that in accordance with previous research (Glaser, 2017), also in this project a two-level perspective of blockchain (fabric and application layer) might help to understand the implications of the technology. Yet, focused on the business implications of the technology, we further uncover along that path. Finally, as we have seen that blockchain affects products (car dossier), business models (customization) and processes (sharing of processes) this supports our choice of the value disciplines (Treacy and Wiersema, 1993) as an academic lens.

\section{Guidelines for Excelling in One Blockchain Value Disciplines}

In the following we summarize our results and discuss the specificities of each blockchain value discipline. Additionally, we derive guidelines for other businesses aiming to excel in one of the three blockchain value disciplines.

\section{Distributed Product Innovation}

Distributed Product Innovation means that blockchain enables co-creating new products and services across organizations in a distributed manner. We have refined the value discipline lens of Treacy and Wiersema (1993), and characterize product innovation when blockchain technology is used as Distributed Product Innovation. This is because the technology now enables companies to collaborate but still share power and thus create innovative artifacts, that serve unserved customer needs. However, being able to do so, companies need to put on their consortium glasses and focus on the customer needs that might exceed their current industries boundaries. As we have seen from the Car Dossier case, blockchain is a technology that allows to collaborate across industries and jointly create a product like the car dossier to previously unserved customer needs by drawing on distributed resources. Prior, a single company was not able to serve customers' needs sufficiently, because they lacked the competences or resources. For example, in the case of the used car market one single company does not possess all data about the car. Thus, to achieve a comprehensive view multiple stakeholder are needed to meet customers' needs accordingly. These customer needs however are not inherent to one company's current primary business focus but rather lay at intersections. Thus, for other companies experimenting with the technology and aiming to create business value through novel products or services, we suggest to join efforts with other players in the same ecosystem. By adapting a holistic view on the ecosystem and collaborating with other experts from related industries they will be able to uncover unsolved potential and innovate products and services for a novel joint market.

\section{Shared Operational Efficiency}

Operational Efficiency when blockchain technology is used, means that it enables companies to minimize overhead costs through sharing processes. As the key value lever lies at the intersection of organizational processes, we have characterized the value discipline with respect to blockchain as shared operational excellence. In our case project there were plenty of examples for resolving inefficiency and eliminating intermediary steps. One example elaborated above was the case of a car import, where authorities like road traffic authority and customs can digitize and share processes with importer businesses. This allows on the one hand authorities to increase customer convenience. On the other hand, it facilitates opportunities for cost reduction for importers. Both resulting in individually optimized business processes from cross-organizational collaboration.

Based on these insights from the Car Dossier case, our suggestions for other companies aiming to create value from the technology through better infrastructure management, is to apply a balanced perspective. On the one hand, jointly target cross-organizational inefficiencies with your partners. On the other hand, focus on the specificities of your own business to leverage the full potential from arising unresolved inefficiencies. Hence, mastering this value discipline requires on the one hand 
a lot of skills in business to business collaboration, on the other hand it also requires an expert knowledge in current business processes to identify and target the greatest inter-organizational inefficiencies that will quickly show great payoffs.

\section{Controlled Customer Intimacy}

Controlled Customer Intimacy refers to the ability of companies to achieve excellence in customer intimacy through blockchain, however, in a customer-controlled manner. We exemplified this through the possibilities of customized insurance, yet, while respecting customers' voice. Thus, as some of our stakeholders have already learned from the project, companies that aim to leverage this potential need to build trust with their customers first. This is because a platform like the one of the Car Dossier project allows increased access to customer data. However, inherent to the characteristics of blockchain it also inhibits unpermitted control. On the one hand, this is necessary to allow companies to trust the data they get from other players in the system. On the other hand, this also introduces greater control over data access for customers. Finally, we also learned that sometimes in the case of a blockchain-based data market like the one the Car Dossier project is building, even multi-party-ownership is possible. Hence, access to data that eventually enables businesses to create value through increased customization of products and/or processes, might require the consent of multiple parties. Thus, the guideline we derive for other companies that rely on a customer relationship business and aim to create value through blockchain, is to focus on building even greater trust relationships with their customers. More specifically they should interpret the term intimacy in a more bilateral sense and build an intimate bilateral relationship, in order to create value through blockchain with the customer. Furthermore, this also requires a better understanding of the data ownership and data structure (especially with respect to multi-party data ownership). An early participation and cocreation of such a complex system might help business to gain a competitive advantage through learnings on how to deal with such new rules as well as through building early relationships with customers as well as data co-creators.

Besides these promising potentials we would also like to acknowledge some boundaries of the value potentials that should not be forgotten. These are on the one hand the boundaries of customer intimacy which need to be respected. Societal questions like reinforcement of a two-class society through too much individualization need to be evaluated carefully. On the other hand, changing operational processes that incorporate authorities are not as simple. Sometimes even legal groundings are needed for that. Yet, the novelty and constant evolution the technology itself makes it hard for practitioners to initiate legal changes. Thus, despite discovered value potential, leveraging it is yet another hurdle.

\section{Approaching Multiple Blockchain Value Disciplines}

While the results and the above-mentioned guidelines show great potential for how individual businesses can realize the value potential from blockchain, there are also certain hurdles we encountered during our exploration. First, in such a big project multiple interest groups need to be managed. As this analysis exemplifies, there is great potential for all stakeholder, however in different ways, or in other words through different value disciplines. Thus, managing these different interests accordingly, to allow all stakeholders to leverage the potential they are after, is a key activity affecting all companies involved in the project. Second, all companies collaborating on the same project for one ecosystem will all have the same potential, independent the industry they are in now. This can induce competition over business potential. Thus, given the multitude of value potential combined with the paradoxon of collaboration and coopetition in such a blockchain project, from our longitudinal observation we can that derive mastering multiple value potentials is certainly a key to success. This is especially the case for platform blockchain projects, that are deployed by multiple stakeholders. As Treacy and Wiersema (1993) already indicated, while excelling in one value discipline is the minimum and mastering two is the future, we agree with that view and take it a step further. Specifically, we argue that while entanglement of the value potentials at the individual business level is still a solid approach, in order to create value from blockchain in an ecosystem, the consortium of stakeholders that deploy the blockchain, need to master multiple value disciplines. In our case project, the car dossier, the initial case that brought together the Car Dossier consortium was the drive to innovate and create a novel product for the used-car market by enabling distributed access to resources and capabilities. However, along the prototyping phase, the stakeholders quickly realized that even great value can be achieved through Shared Operational Efficiency. Thus, while bearing in mind the initial business case as well as the other value potentials, the focus of development quickly shifted to enable early value creation through reduced cost and increased efficiency by sharing operational processes. This is of interest for all stakeholders as it enables all involved equally to create value from the platform's data and the shared infrastructure through increasing efficiency. Thus, based on these insights for other projects that aim to create value from blockchain, we recommend to:

\section{- design for all three blockchain value disciplines, but \\ - implement and execute shared operational efficiency first.}

By addressing first the shared operational efficiency potential from blockchain technology this will allow the consortium to achieve a common ground for all involved stakeholders and enable the necessary collaboration. At the same time, in order to allow for competition later, the other blockchain value disciplines should be kept in mind during the development of blockchain architecture. This means that the ability to jointly create novel products and services by drawing on distributed resources and capabilities as well as to leverage potential through controlled customer intimacy need to be embedded early in the system architecture and governance of the platform. For example, distributed product innovation in the case of the car ecosystem requires to incorporate and consider a fair data market mechanism that will incentivize 
and reward all relevant stakeholders adequality. Controlled customer intimacy requires an architecture that incorporates adequate privacy protection. Thus, designing for three value potentials but focusing on shared operational efficiency first, can be a successful approach to manage multiple value disciplines in a blockchain project where multiple stakeholders are involved.

\section{CONCLUSION}

In this paper we address the little attention that was given to blockchain from a business perspective by explicating how businesses can create value from a decentralized car ledger. Thus, we answer our research question, by showing how blockchain enables distributed product innovation, shared operational efficiency, and controlled customer intimacy.

Furthermore, based on the results from the Car Dossier project, we derive guidelines for other businesses aiming to create value from blockchain. More specifically, we propose how other businesses should approach each blockchain value discipline and give recommendations on why and how blockchain projects in ecosystems should master multiple blockchain value potentials.

These insights are valuable not least for (1) academia, as we add to the limited discourse on business potential from blockchain by applying a scientific lens to the value creation and hence providing first answers to open research questions; (2) businesses, through disclosing insights in an advanced blockchain project in a highly-competitive market and providing guidelines for other businesses; (3) society as we emphasize both, the necessity of legislators for adapting and loosening legislation to allow leveraging efficiencies, but also keeping an eye on regulations with respect to customer protection. Yet, our paper has a few limitations. First, our analysis is based solely on the findings of one blockchain project. Thus, we recognize future research will be needed to test the generalizability and the applicability of our findings in the selected, and in other domains. Second, even though our project moved beyond the mere prototyping phase, it is still in an early market entry phase, thus the proposed value potential will require testing in practice. Third, we acknowledge the generality of the approach to define the business value of blockchain projects and the need for more fine-grained analysis. We aim to address this deficit through future research, as part of our ongoing collaboration with the Car Dossier consortium. Finally, it has to be noted that blockchain itself is still a recent innovation that might experience further developments which could impact the value creation logic. Thus, our findings should be viewed as an initial step toward a more holistic understanding of the business potential from blockchain.

\section{DATA AVAILABILITY STATEMENT}

The datasets generated for this study are available on request to the corresponding author.

\section{ETHICS STATEMENT}

All interviews and workshops were conducted in the course of this Innosuisse project and under the written consent of our project partner provided in a cooperation agreement.

\section{AUTHOR CONTRIBUTIONS}

IB, LZ, FL, and GS contributed to the conception and design of the study. FL and IB conducted and coded the interviews. The codebook was crosschecked by FL, LZ, and IB. IB wrote the whole manuscript. All authors contributed to manuscript revision, read and approved the submitted version.

\section{FUNDING}

The Blockchain Car Dossier research project has been funded by Innosuisse, a Swiss innovation agency. It is a federal entity under public law with a separate legal personality. Innosuisse's role is to promote science-based innovation in the interest of industry and society in Switzerland. The Car Dossier project (26920.1 PFES-ES) consists of six partners, Adnovum, AXA Winterthur, AMAG, Mobility, Road Traffic Authority of the Canton Aargau, University of Zurich, and the Lucerne University of Applied Sciences. Both Universities, the University of Zurich as well as the Lucerne University of Applied Sciences, received financial compensation for their work within the Car Dossier project. Ninety percent of this compensation was provided from the Innosuisse (the federal institution), the remaining $10 \%$ were provided by the partners (as required by Innosuisse): AdNovum, AMAG, Mobility and the AXA Winterthur. The road traffic authority did not provide any financial or non-financial compensation. The project was funded for the duration of the project (24 months), from October 2017 until October 2019.

\section{ACKNOWLEDGMENTS}

We thank all partners for their involvement and feedback, and all reviewers for critical comments that enhanced the research. The manuscript is based on the conference publication ${ }^{1}$ from the 52nd Hawaii International Conference on System Sciences (HICSS). The authors confirm the right to reuse the material and confirm that a major part of this work is new.

\section{SUPPLEMENTARY MATERIAL}

The Supplementary Material for this article can be found online at: https://www.frontiersin.org/articles/10.3389/fbloc. 2019.00030/full\#supplementary-material

\footnotetext{
${ }^{1}$ Bauer, I., Zavolokina, L., Leisibach, F., and Schwabe, G. (2018). Exploring blockchain value creation: the case of the car ecosystem, In Proceedings of the 52nd Hawaii International Conference on System Sciences.
} 


\section{REFERENCES}

Akerlof, G. A. (1970). The market for 'Lemons': quality uncertainty and the market mechanism. Q. J. Econ. 84, 488-500. doi: 10.2307/1879431

Avital, M., Beck, R., King, J., Rossi, M., and Teigland, R. (2016). "Jumping on the blockchain bandwagon: lessons of the past and outlook to the future," in 37th ICIS Proceedings (Dublin).

Bauer, I., Zavolokina, L., and Schwabe, G. (2019). Is there a market for trusted car data? Electronic Mark. 1-15. doi: 10.1007/s12525-019-00368-5

Beck, R., Avital, M., Rossi, M., and Thatcher, J. B. (2017). Blockchain technology in business and information systems research. Bus. Inf. Syst. Eng. 59, 381-384. doi: 10.1007/s12599-017-0505-1

Beck, R., Stemi, J. C., Lollike, N., and Malone, S. (2016). "Blockchain - the gateway to trust-free cryptographic transactions," in Twenty-Fourth European Conference on Information Systems (ECIS) (Istanbul), 1-14.

Beck, R., Weber, S., and Gregory, R. W. (2013). Theory-generating design science research. Inf. Syst. Front. 15, 637-651. doi: 10.1007/s10796-012-9342-4

Chen, P. P.-S. (1976). The Entity-Relationship Model: Towards a Unified View of Data. Massachusetts Institute of Technology.

Chesbrough, H. (2002). The role of the business model in capturing value from innovation: evidence from xerox corporation's technology spin-off companies. Ind. Corp. Change 11, 529-555. doi: 10.1093/icc/11.3.529

Chesbrough, H. W. (2003). Open Innovation: The New Imperative for Creating and Profiting from Technology. Boston, MA: Harvard Business School Press.

Davidson, S., de Filippi, P., and Potts, J. (2016). "Economics of Blockchain," in Public Choice Conference (Fort Lauderdale, FL). doi: 10.2139/ssrn.2744751

de Kruijff, J., and Weigand, H. (2017). "Understanding the blockchain using enterprise ontology," in Proceedings of the 29th International Conference on Advanced Information Systems Engineering (CAiSE 2017), eds E. Dubois and K. Pohl (Cham: Springer Verlag), 29-43.

Desouza, K. C. (2011). Intrapreneurship: Managing Ideas Within Your Organization. Toronto, ON: University of Toronto Press.

Eichen, M. (2006). Value disciplines: a lens for successful decision making in IT. Educ. Q. 29, 32-39.

Fichman, R. G., Dos Santos, B. L., and Zheng, Z. (2014). Digital innovation as a fundamental and powerful concept in the information systems curriculum. MIS Q. 38, 329-343. doi: 10.25300/MISQ/2014/38.2.01

Glaser, F. (2017). "Pervasive decentralisation of digital infrastructures: a framework for blockchain enabled system and use case analysis," in The 50th Hawaii International Conference on System Sciences (Waikoloa Village, HI)

Gregor (2006). The nature of theory in information systems. MIS Q. 30:611. doi: $10.2307 / 25148742$

Gregor, S., Müller, O., and Seidel, S. (2013). "Reflection, abstraction and theorizing in design and development research," in Proceedings of the 21st European Conference on Information Systems (Utrecht), Vol. 7-1. 13.

Hagler, J., and Singer, M. (1999). Unbundling the corporation. Harvard Business Review, Organizational Structure. 21.

Hamm, S. (2016). How Businesses and Governments Can Capitalize on Blockchain. Retrieved from: https://www.ibm.com/blogs/think/2016/03/16/ how-businesses-and-governments-can-capitalize- on-blockchain/ (accessed May 20, 2018).

Hevner, A. R., March, S. T., Park, J., and Ram, S. (2004). Design science in information systems research. MIS Q. 1, 75-105. doi: 10.2307/25148625

Iansiti, M., and Lakhani, K. R. (2017). The truth about blockchain. Harvard Business Review. 11.

Lacity, M. (2018). Addressing Key challenges to making enterprise blockchain applications a reality. MIS Q. Execut. 17, 201-222.

Lacity, M. C., Moloney, K., and Ross, J. W. (2018). Blockchain: How to Position Your Company for the Inevitable. MIT Sloan School of Management, MIT CISR.

Li, W., Sforzin, A., Fedorov, S., and Karame, G. O. (2017). "Towards scalable and private industrial blockchains," in Proceedings of the ACM Workshop on Blockchain, Cryptocurrencies and Contracts - BCC '17, (Abu Dhabi: ACM Press), 9-14.

Lindman, J., Rossi, M., and Virpi, K. T. (2017). "Opportunities and risks of blockchain technologies in payments - a research agenda," in Proceedings of the 50th Hawaii International Conference on System Sciences (Waikoloa Village, $\mathrm{HI})$.
Meiklejohn, S., Pomarole, M., Jordan, G., Levchenko, K., McCoy, D., Voelker, G. M., et al. (2016). A fistful of Bitcoins: characterizing payments among men with no names. Commun. ACM 59, 86-93. doi: 10.1145/2896384

Mengelkamp, E., Notheisen, B., Beer, C., Dauer, D., and Weinhardt, C. (2018). A blockchain-based smart grid: towards sustainable local energy markets. Comput. Sci. Res. Dev. 33, 207-214. doi: 10.1007/s00450-017-0360-9

Morabito, V. (2017). Business Innovation Through Blockchain. Cham: Springer International Publishing.

Mougayar, W. (2016). The Business Blockchain: Promise, Practice, and Application of the Next Internet Technology. Hoboken, NJ: Wiley.

Myers, M. D., and Newman, M. (2007). The qualitative interview in IS research: examining the craft. Inf. Organ. 17, 2-26. doi: 10.1016/j.infoandorg.2006.11.001

Naerland, K., Müller-Bloch, C., Beck, R., and Palmund, S. (2017). "Blockchain to rule the waves - nascent design principles for reducing risk and uncertainty in decentralized environments," in Thirty Eighth International Conference on Information Systems (Seoul).

Notheisen, B., Cholewa, J. B., and Shanmugam, A. P. (2017). Trading real-world assets on blockchain. Bus. Inf. Syst. Eng. 59, 425-440. doi: 10.1007/s12599-017-0499-8

Osterwalder, A., and Pigneur, Y. (2010). Business Model Generation. Hoboken, NJ: John Wiley \& Sons, Inc.

Peppard, J., and Ward, J. (2004). Beyond strategic information systems: towards an IS capability. J. Strateg. Inf. Syst. 13, 167-194. doi: 10.1016/j.jsis.2004.02.002

Risius, M., and Spohrer, K. (2017). A blockchain research framework: what we (don't) know, where we go from here, and how we will get there. Bus. Inf. Syst. Eng. 59, 385-409. doi: 10.1007/s12599-017-0506-0

Rückeshäuser, N. (2017). “Typology of distributed ledger based business models," in Proceedings of the 25th European Conference on Information Systems (ECIS) (Guimarães), 2202-2217.

Saldaña, J. (2009). The Coding Manual for Qualitative Researchers. Los Angeles, CA: Sage.

Seebacher, S., and Schüritz, R. (2017). "Blockchain technology as an enabler of service systems: a structured literature review," in Exploring Services Science. IESS 2017. Lecture Notes in Business Information Processing, Vol. 279, eds S. Za, M. Drăgoicea, M. Cavallari (Cham: Springer).

Sharples, M., and Domingue, J. (2016). "The blockchain and kudos: a distributed system for educational record, reputation and reward," in Adaptive and Adaptable Learning, eds K. Verbert, M. Sharples, and T. Klobučar (Springer International Publishing), 490-496.

Shirer, M., Goepfert, J., and Soohoo, S. (2019). Worldwide blockchain spending forecast to reach $\$ 2.9$ billion in 2019 , according to new IDC spending guide. IDC - Analyze the Future. Retrieved from: https://www.idc.com/getdoc.jsp? containerId=prUS44898819

Teece, D. J. (2007). Explicating dynamic capabilities: the nature and microfoundations of (sustainable) enterprise performance. Strateg. Manag. J. 28, 1319-1350. doi: 10.1002/smj.640

Teece, D. J. (2010). Business models, business strategy and innovation. Long Range Plann. 43, 172-94. doi: 10.1016/j.lrp.2009.07.003

Tidd, J., and Bessant, J. (2011). Managing Innovation: Integrating Technological, Market and Organizational Change. John Wirley \& Sons.

Treacy, M., and Wiersema, F. (1993). Customer intimacy and other value disciplines. Harvard Business Review. 12.

Treiblmaier, H. (2018). The impact of the blockchain on the supply chain: a theorybased research framework and a call for action. Supply Chain Manag. Int. J. 23, 545-559. doi: 10.1108/SCM-01-2018-0029

Tschorsch, F., and Scheuermann, B. (2016). "Bitcoin and beyond: a technical survey on decentralized digital currencies," IEEE Commun. Surv. Tutorials 18, 2084-2123. doi: 10.1109/COMST.2016.2535718

Weber, R. P. (1990). Basic Content Analysis. Thousand Oaks, CA: Sage.

Weston, C., Gandell, T., Beauchamp, J., McAlpine, L., Wiseman, C., and Beauchamp, C. (2001). Analyzing interview data: the development and evolution of a coding system. Qual. Sociol. 24, 381-400. doi: 10.1023/A:1010690908200

Wüst, K., and Gervais, A. (2017). Do You Need A Blockchain?. Retrieved from: https://eprint.iacr.org/2017/375.pdf

Xu, X., Weber, I., Staples, M., Zhu, L., Bosch, J., Bass, L., et al. (2017). “A taxonomy of blockchain-based systems for architecture design.” in 2017 
IEEE International Conference on Software Architecture (ICSA) (Gothenburg: IEEE), 243-252.

Yoo, Y., Henfridsson, O., and Lyytinen, K. (2010). The new organizing logic of digital innovation: an agenda for information systems research. Inf. Syst. Res. 21, 724-735. doi: 10.1287/isre.1100.0322

Zavolokina, L., Miscione, G., and Schwabe, G. (2018). Buyers of 'lemons': how can a blockchain platform address buyers' needs in the market for 'lemons'? Electron. Markets 1-13

Zavolokina, L., Ziolkowski, R., Bauer, I., and Schwabe, G. (2020). Management, Governance and Value Creation in a Blockchain Consortium. MISQE (Forthcomming).
Conflict of Interest: The authors declare that the research was conducted in the absence of any commercial or financial relationships that could be construed as a potential conflict of interest.

Copyright (c) 2020 Bauer, Zavolokina, Leisibach and Schwabe. This is an open-access article distributed under the terms of the Creative Commons Attribution License (CC $B Y)$. The use, distribution or reproduction in other forums is permitted, provided the original author(s) and the copyright owner(s) are credited and that the original publication in this journal is cited, in accordance with accepted academic practice. No use, distribution or reproduction is permitted which does not comply with these terms. 